\title{
Management of Patients with Locally Advanced Breast Cancer
}

\author{
Marie Catherine Lee, $\mathrm{MD}^{\mathrm{a}}$, \\ Lisa A. Newman, MD, MPH, FACS ${ }^{\mathrm{b}, *}$ \\ ${ }^{a}$ Department of Surgery, University of Michigan, 1500 East Medical Center Drive, \\ 3216 A Cancer Center/Box 0932, Ann Arbor, MI 48109, USA \\ ${ }^{\mathrm{b}}$ University of Michigan Comprehensive Cancer Center, Breast Care Center, \\ 1500 East Medical Center Drive, Ann Arbor, MI 48167, USA
}

Locally advanced breast cancer (LABC) continues to be a significant problem in the United States and a common breast cancer presentation worldwide. LABC generally is defined by bulky primary chest wall tumors and/or extensive adenopathy. This includes patients with $\mathrm{T} 3(>5 \mathrm{~cm})$ or T4 tumors (chest wall fixation or skin ulceration and/or satellitosis) and N2/N3 disease (matted axillary and/or internal mammary metastases) [1]. Of note, recent studies demonstrate that prolonged survival can be achieved in patients with metastatic disease limited to the supraclavicular nodes after appropriate multimodality breast cancer treatment [1,2]. As a result, the sixth edition of the American Joint Committee on Cancer (AJCC) staging system now includes isolated supraclavicular metastases in the stage III/LABC disease category [3]. According to the American College of Surgeons National Cancer Data Base, approximately $6 \%$ of breast cancers in the United States present as stage III breast cancer disease [4]. Five-year survival for stage III breast cancer is approximately $50 \%$, compared with $87 \%$ for stage I.

The extent to which $\mathrm{LABC}$ represents neglect and delayed diagnosis versus aggressive tumor biology is unclear. Data from the Surveillance, Epidemiology, and End Results (SEER) program reveal that the proportion of LABC is notably higher among women of African, Hispanic, and Native American descent compared with white and Asian Americans, contributing to increased mortality in these populations. These disparities partly reflect socioeconomic and health care access inequalities, but parallel variations in the incidence of breast cancer based on country of origin also suggest

* Corresponding author.

E-mail address: lanewman@umich.edu (L.A. Newman). 
the existence of environmental and genetic factors. This article discusses the history of LABC treatment and the preferred diagnostic-therapeutic management sequence. The evolving subjects of breast conservation, immediate breast reconstruction, optimal neoadjuvant treatment, and lymphatic mapping in patients who have LABC also are addressed.

\section{Evolution of treatment options in locally advanced breast cancer}

Surgeons historically have been at the forefront of investigating LABC treatment. Haagensen and Stout [5] at Columbia University provided early data regarding the dismal results of radical mastectomy alone as treatment for LABC over 60 years ago, reporting 5-year local recurrence and survival rates of $46 \%$ and $6 \%$, respectively. This experience led to the definition of inoperable LABC when patients presented with extensive breast skin edema or satellitosis, intercostal/parasternal nodules, arm edema, supraclavicular metastases, or inflammatory breast cancer. In contrast, grave local signs of LABC were poor prognostic features, but not contraindications to resection. These included ulceration, limited skin edema, fixation to the pectoralis muscle, and bulky axillary adenopathy.

Therapeutic doses of chest wall radiation were similarly inadequate in controlling LABC. Studies from the 1970s and 1980s by the Joint Center for Radiation Therapy, Guy's Hospital, and the Mallincrodt Institute of Radiology all revealed excessively high failure rates, with 5-year local recurrence rates ranging from $46 \%$ to $72 \%$, and survival rates of $16 \%$ to $30 \%$ [6-8]. Combined treatment with radiation plus surgery was also attempted in this era [9-11], but yielded no significant improvement in disease control.

Preoperative chemotherapy protocols (also known as neoadjuvant or induction chemotherapy) revolutionized LABC care; this approach is now standard for patients with bulky breast and/or axillary disease. Early concerns regarding this approach were based on the potentially negative effects of preoperative chemotherapy on: surgical complication rates, the prognostic value of the axillary staging, and overall survival after delayed surgery. Clinical investigations reported during the 1980s and 1990s addressed and alleviated these concerns.

Comparable operative morbidity was demonstrated in a study of nearly 200 LABC patients treated with mastectomy, approximately half of whom received preoperative chemotherapy; neoadjuvant patients actually had a lower rate of postoperative seroma formation [12]. Danforth and colleagues [13] similarly reported that preoperative chemotherapy neither adversely affects surgical complication rates nor delays postoperative treatment. Most patients are ready for surgery 3 to 4 weeks after the last chemotherapy cycle, when absolute neutrophil and platelet counts are greater than 1500 and 100,000, respectively.

The prognostic value of axillary staging in LABC patients that have received neoadjuvant chemotherapy followed by axillary lymph node 
dissection was confirmed by McCready and colleagues [14]. A study of 136 LABC cases undergoing modified radical mastectomy following induction chemotherapy revealed that patients with no axillary metastases in the postchemotherapy mastectomy specimen had a nearly $80 \% 5$-year survival rate. In contrast, fewer than $10 \%$ of patients who had 10 or more positive nodes survived 5 years, and patients who had an intermediate number of residual nodes had intermediate survival rates.

The issue of whether neoadjuvant chemotherapy can improve survival in LABC patients remains controversial. However several prospective trials conducted internationally have clearly demonstrated that delaying surgery while systemic therapy is being delivered does not compromise outcome when compared to the sequence of surgery first, followed by postoperative chemotherapy. It has been shown that neoadjuvant therapy does not worsen survival but it does improve resectability. Approximately $80 \%$ of patients have significant primary tumor shrinkage; only $2 \%$ to $3 \%$ have signs of progression [15-17]. Fears of a missed window of opportunity to resect chest wall disease therefore are unfounded, and preoperatively treated patients often are improved operative candidates. Resection is essential for documenting chemotherapy response and achieving locoregional control, as clinical assessment is notoriously unreliable [18,19]. Table 1 [20-22] summarizes results of various LABC treatment strategies over the past several decades.

Currently, optimal control is achieved with preoperative chemotherapy followed by surgery and radiation. Preoperative versus postoperative chemotherapy have been directly compared in women with LABC and also in women with early stage breast cancer. These prospective clinical trials have demonstrated overall survival equivalence for the two sequences, confirming the oncologic safety of the neoadjuvant approach [23-30]. Since patients with $\mathrm{LABC}$ benefit from the tumor downstaging and improved resectability that can be achieved with neoadjuvant chemotherapy, this sequence has become the preferred approach for patients with bulky, locally advanced disease at time of diagnosis.

\section{Diagnostic and therapeutic management sequence}

Establishing a tissue diagnosis is the initial priority on presentation of LABC. In many patients, core biopsy of the tumor, either freehand or under ultrasound guidance, is diagnostic. Core needle is preferred over fine needle aspiration, as cytology is insufficient to confirm invasion. Additionally, multiple cores should be extracted both to confirm invasive cancer and to evaluate hormone receptor status and HER2/neu expression. This is critical, because palpable ductal carcinoma in situ (DCIS) does exist, and induction chemotherapy is inappropriate for DCIS, even with microinvasion. A negative or nondiagnostic needle biopsy with a clinically suspicious lesion is an indication to proceed to diagnostic open biopsy; cases characterized by skin involvement may be amenable to punch biopsy. If matted, fixed, 
Table 1

Locally advanced breast cancer outcome based on treatment delivered and sequence of multimodality therapy

\begin{tabular}{|c|c|c|c|c|c|c|}
\hline $\begin{array}{l}\text { Treatment } \\
\text { approach }\end{array}$ & $\begin{array}{l}\text { Components and } \\
\text { sequence of } \\
\text { treatment }\end{array}$ & Study & Samp & size & $\begin{array}{l}5 \text {-year local } \\
\text { recurrence } \\
\text { rate }(\%)\end{array}$ & 5 -year survival (\%) \\
\hline \multirow[t]{4}{*}{ Single modality } & Surgery only & $\begin{array}{l}\text { Haagensen and Stout, } \\
1943[5]\end{array}$ & 35 & & $46 \%$ & $6 \%$ \\
\hline & & $\begin{array}{l}\text { Arnold and Lesnick, } \\
1979[10]\end{array}$ & 50 & & $50 \%$ & $33 \%$ \\
\hline & Radiation (XRT) only & Rubens, 1977 [8] & 184 & & $72 \%$ & $18 \%$ \\
\hline & & Harris, $1983[6]$ & 137 & & $46 \%$ & $30 \%$ \\
\hline \multirow[t]{9}{*}{ Dual modality } & $\mathrm{XRT} \rightarrow$ surgery & $\begin{array}{l}\text { Arnold and Lesnick, } \\
1979[10]\end{array}$ & 54 & & $70 \%$ & $30 \%$ \\
\hline & & Townsend, 1985 [9] & 53 & & $11 \%$ & $47 \%$ \\
\hline & Surgery $\rightarrow$ XRT & $\begin{array}{l}\text { Arnold and Lesnick, } \\
1979[10]\end{array}$ & 122 & & $70 \%$ & $32 \%$ \\
\hline & & $\begin{array}{l}\text { Montague and Fletcher, } \\
1985 \text { [11] }\end{array}$ & 132 & & $13 \%$ & $43 \%$ (at 10 years) \\
\hline & $\begin{array}{l}\text { Chemotherapy } \\
\rightarrow \text { surgery }\end{array}$ & Valagussa, 1983 [20] & 205 & & $18 \%$ & (c) \\
\hline & & Perloff, 1988 [16] & 43 & & $19 \%$ & Median survival 39 months \\
\hline & $\begin{array}{l}\text { Chemotherapy } \\
\quad \rightarrow \text { XRT }\end{array}$ & Valagussa, 1983 [20] & 198 & & $36 \%$ & $35 \%$ \\
\hline & & Perloff, 1988 [16] & 44 & & $27 \%$ & Median survival 39 months \\
\hline & Surgery $\rightarrow$ chemotherapy & Olson, 1997 [21] & 148 & & $20 \%$ & $65 \%$ (estimated from graph) \\
\hline \multirow[t]{4}{*}{ Triple modality } & $\begin{array}{l}\text { Chemotherapy } \rightarrow \text { surgery } \\
\quad \rightarrow \text { XRT }\end{array}$ & Kuerer, 1999 [38] & 372 & $\mathrm{pCR} ; \mathrm{n}=43$ & $5 \%$ & $89 \%$ \\
\hline & & & & $<\mathrm{pCR} ; \mathrm{n}=329$ & $9 \%$ & $64 \%$ \\
\hline & & Cance, 2002 [22] & 62 & & $14 \%$ & $76 \%$ \\
\hline & $\begin{array}{l}\text { Surgery } \rightarrow \text { chemotherapy } \\
\quad \rightarrow \text { XRT }\end{array}$ & Olson, 1997 [21] & 164 & & $9 \%$ & $66 \%$ (estimated from graph) \\
\hline
\end{tabular}


axillary, or supraclavicular adenopathy is present, fine needle aspiration of the nodes may be performed for staging.

Prompt bilateral mammography in this setting is essential, regardless of patient age and date of her most recent study. Diffuse, suspicious microcalcifications or multiple lesions in different quadrants indicate multicentric disease, and are a contraindication to breast conservation therapy (BCT). Patients who have these findings should be informed that they will require mastectomy regardless of their neoadjuvant therapy response [31]. If BCT is a consideration, a microclip placed at the primary tumor is essential before the initiation of induction therapy, unless the primary tumor is associated with a cluster of microcalcifications. Up to $50 \%$ of patients may have a complete clinical response, and an unmarked primary site eliminates the possibility of breast preservation in these cases, as the lumpectomy site will no longer be adequately defined.

Breast and axillary ultrasound frequently yield valuable information regarding the extent of disease. In particular, axillary ultrasound can be used for image-guided FNA [32,33]; ultrasound detection of apical axillary/infraclavicular nodal metastases has been shown to provide important prognostic information [34]. Unfortunately, ultrasound has an approximately $20 \%$ falsenegative rate, as metastases smaller than $5 \mathrm{~mm}$ in size are undetectable.

Once a tissue diagnosis is established, LABC patients should undergo multidisciplinary review before treatment. The multidisciplinary team should include surgical, medical and radiation oncologists, pathologists, radiologists, and plastic surgeons, creating a unified treatment proposal and thereby minimizing the possibility that inconsistent messages will be delivered to the patient by the various specialists involved with the management plan. A baseline bone scan, and chest, abdominal, and pelvic CT scans are recommended for detection of metastatic disease. Directed radiographs to sites of new bone pain, or a head CT scan for new neurologic symptoms are also appropriate in selected cases. The yield of a metastatic work-up in an asymptomatic, early breast cancer patient is approximately $2 \%$ to $3 \%$, but this risk rises to $30 \%$ in LABC [35]. With radiologic evidence of metastatic disease, the role of surgery is controversial. Some data suggest a survival benefit with aggressive breast surgery despite the presence of distant organ metastases. However, these retrospective analyses are limited by an inability to control for inherent selection biases [36].

Patients receiving preoperative chemotherapy should be reassessed after one or two cycles and again at the completion of therapy to document response and explore surgical options. Repeat imaging may be useful at the interim evaluation. If minimal or no response is observed after the initial cycles, a decision should be made to either proceed with surgery or to cross over to a different systemic therapy. Salvage surgery allows for a full pathologic evaluation, facilitating decisions on adjuvant therapy. If an alternative regimen is selected, then reassessment after two cycles of the crossover treatment is necessary. Follow-up imaging is essential after 
complete delivery of neoadjuvant therapy for final preoperative surgical planning. Occasional patients that appeared to have a unicentric cancer density at presentation will experience unmasking of extensive microcalcifications or multicentric satellite tumors after chemotherapy response, and these findings may convert them to mandatory mastectomy cases.

Subset analyses of the phase III studies reveal that patients who have a complete pathologic response ( $\mathrm{pCR}$ ) have a statistically significant survival benefit, substantiating the concept that primary tumor response is a reliable surrogate for chemotherapy effect on micrometastases. In the NSABP B-18 trial [37], patients with stage I to III breast cancer randomized to receive preoperative doxorubicin and Cytoxan and who experienced a pCR had a 5-year overall survival of $86 \%$, statistically superior to the outcome seen in all other study participants. Predictors of a pCR include relatively smaller size primary breast tumors, estrogen receptor negativity, and highgrade lesions [38].

\section{Controversies in the management of locally advanced breast cancer patients}

\section{Breast conservation therapy versus mastectomy}

The magnitude of the clinical response to neoadjuvant chemotherapy in LABC prompted investigations of breast conservation for selected patients. Initially, whether the clinical response correlated with either a concentric diminution of the initial mass or a primary tumor that left foci of malignant cells in the remaining parenchyma was unclear. Singletary and colleagues [39] conducted a feasibility study to evaluate the pathologic extent of residual disease in 136 LABC patients treated with induction chemotherapy. Extensive scrutiny of the postchemotherapy mastectomy specimens revealed that the residual tumor would have been amenable to lumpectomy in approximately $25 \%$ of patients.

From this and other studies [31], several criteria for BCT in postneoadjuvant $\mathrm{LABC}$ have been adopted widely:

- Patient desire for breast preservation

- Absence of multicentric disease (tumors in different quadrants of the breast)

- Absence of diffuse microcalcifications on mammogram

- Absence of skin involvement consistent with inflammatory breast cancer

- Residual tumor mass amenable to a margin-negative lumpectomy resection

Prospective, randomized controlled clinical trial data have confirmed acceptable rates of local control among LABC patients undergoing breast-conserving surgery after neoadjuvant therapy. Several prospective, randomized controlled trials of neoadjuvant versus adjuvant/postoperative chemotherapy have included cohorts of patients with Stage III disease/ LABC. Data from these studies have documented acceptably low rates of 
local recurrence in LABC patients undergoing breast-conserving surgery after neoadjuvant chemotherapy (Table 2) [40,41]. The NSABP B-18 investigators did note a trend toward higher local recurrence rates among patients requiring preoperative downstaging in order to become lumpectomy eligible $(15 \%$ versus $7 \%)$. This is not necessarily surprising, however, as postlumpectomy local recurrence is one manifestation of aggressive tumor biology, and larger tumors are more likely to demonstrate aggressive behavior, even after mastectomy. Postmastectomy radiation (PMRT) is recommended for patients with T3 tumors because of this concept [42]. Of note, the NSABP defines a negative margin as the absence of tumor cells at the cut, inked specimen margin; wider margins are probably preferable in patients receiving neoadjuvant chemotherapy.

\section{Optimal preoperative systemic therapy regimen}

Currently, doxorubicin-based chemotherapy is the most widely-studied induction regimen, and it results in at least $50 \%$ tumor shrinkage in more than $75 \%$ of cases. The NSABP B-27 protocol randomized patients with resectable breast cancer to one of three neoadjuvant treatment arms: (1) doxorubicin and Cytoxan alone; (2) doxorubicin, Cytoxan, and docetaxel; or (3) preoperative doxorubicin and Cytoxan followed by postoperative docetaxel. Preliminary data [43] reveal a pCR rate of $26 \%$ associated with the addition of docetaxel to the preoperative regimen. Similarly, the University of Texas M.D. Anderson Cancer Center [44] has reported a pCR rate of nearly $30 \%$ in patients treated with preoperative doxorubicin, Cytoxan, 5-fluorouracil, and weekly Taxol.

The Aberdeen trial investigated whether the number of chemotherapy cycles is a stronger predictor of tumor response compared with chemotherapy type $[45,46]$. One hundred sixty-two patients with primary tumors of at least $3 \mathrm{~cm}$ were given four cycles of doxorubicin-based chemotherapy. Responders then were randomized to either four more cycles of doxorubicin, or crossed over to four cycles of docetaxel, so that all patients received eight preoperative cycles of chemotherapy. Among the responders, the $\mathrm{pCR}$ rate for the doxorubicin-only group was $16 \%$, compared with $34 \%$ for the responders randomized to the crossover docetaxel regimen $(P=.04)$, demonstrating that the nature of the agent is more important than the quantity. They also showed that poor responders may benefit from crossover to an alternative regimen. Survival analyses at 3 years also suggest improved outcomes for patients on docetaxel plus doxorubicin [46].

Neoadjuvant endocrine therapy for estrogen receptor-positive LABC also holds great promise. Three-to-four months of therapy are preferred for an adequate response assessment, and preliminary studies suggest that aromatase inhibitors such as letrozole are more effective than tamoxifen $[47,48]$. Other neoadjuvant regimens currently being evaluated include trastuzumab, Navelbine, capecitabine, and gemcitabine. Microarray technology 
Table 2

Randomized studies of neoadjuvant versus adjuvant chemotherapy for breast cancer

\begin{tabular}{|c|c|c|c|c|c|c|c|c|c|c|}
\hline \multirow[b]{2}{*}{ Study } & \multirow[b]{2}{*}{$\mathrm{N}$} & \multirow[b]{2}{*}{ Stages } & \multirow[b]{2}{*}{ Treatment } & \multirow[b]{2}{*}{$\begin{array}{l}\text { Median } \\
\text { follow-up }\end{array}$} & \multicolumn{2}{|l|}{$\mathrm{BCT}$ rate } & \multicolumn{2}{|c|}{$\begin{array}{l}\text { Local recurrence } \\
\text { after BCT }\end{array}$} & \multicolumn{2}{|c|}{$\begin{array}{l}\text { Overall survival } \\
\text { at median follow-up }\end{array}$} \\
\hline & & & & & $\begin{array}{l}\text { Preoperative } \\
\text { chemotherapy }\end{array}$ & $\begin{array}{l}\text { Postoperative } \\
\text { chemotherapy }\end{array}$ & $\begin{array}{l}\text { Preoperative } \\
\text { chemotherapy }\end{array}$ & $\begin{array}{l}\text { Postoperative } \\
\text { chemotherapy }\end{array}$ & $\begin{array}{l}\text { Preoperative } \\
\text { chemotherapy }\end{array}$ & $\begin{array}{l}\text { Postoperative } \\
\text { chemotherapy }\end{array}$ \\
\hline $\begin{array}{l}\text { Institut } \\
\quad \text { Curie } \\
{[25,26,40,41]}\end{array}$ & 414 & IIA-IIIA & $\begin{array}{l}\mathrm{FAC} \times 4 \rightarrow \mathrm{XRT} \pm \mathrm{S} \\
\text { versus } \mathrm{XRT} \pm \mathrm{S} \rightarrow \\
\mathrm{FAC} \times 4 \text { ( } \mathrm{S} \text { reserved } \\
\text { for incomplete } \\
\text { responders) }\end{array}$ & $66 \mathrm{mo}$ & $82 \%$ & $77 \%$ & $24 \%$ & $18 \%$ & $86 \%$ & $78 \%$ \\
\hline $\begin{array}{l}\text { Royal } \\
\text { Marsden } \\
{[27,28]}\end{array}$ & 309 & I-IIIB & $\begin{array}{l}\text { Tam }+\mathrm{MM} \pm \mathrm{M} \times 4 \rightarrow \\
\mathrm{S} \rightarrow \mathrm{Tam}+ \\
\mathrm{MM} \pm \mathrm{M} \times 4 \text { Versus } \\
\mathrm{S} \rightarrow \mathrm{MM} \pm \mathrm{M} \times 8+ \\
\text { Tam }\end{array}$ & $48 \mathrm{mo}$ & $89 \%$ & $78 \%$ & $3 \%^{\mathrm{b}}$ & $4 \%^{\mathrm{b}}$ & $80 \%^{\mathrm{a}}$ & $80 \%^{\mathrm{a}}$ \\
\hline $\begin{array}{l}\text { NSABP } \\
{[29,30]}\end{array}$ & 1523 & I-IIIA & $\begin{array}{l}\mathrm{AC} \times 4 \rightarrow \mathrm{S} \text { Versus } \mathrm{S} \rightarrow \\
\mathrm{AC} \times 4\end{array}$ & $72 \mathrm{mo}$ & $68 \%$ & $60 \%$ & $7.9 \%$ & $5.8 \%$ & $80 \%^{\mathrm{c}}$ & $80 \%^{\mathrm{c}}$ \\
\hline
\end{tabular}

Abbreviations: BCT, breast conservation therapy; EVM, epirubicin vincristine methotrexate; FAC 5, -fluorouracil doxorubicin cyclophosphamide; MM \pm M, mitoxantrone methotrexate with or without mitomycin-C; MRM, modified radical mastectomy; MTV, mitomycin C thiotepa vindesine; NA, not applicable; S, surgery; Tam, Tamoxifen; XRT, radiation.

${ }^{a}$ Rate estimated from graph.

b Local recurrence rates reported for lumpectomy and mastectomy patients combined.

${ }^{\mathrm{c}}$ Overall survival rate at 5 years. 
and gene expression profiling are also being explored to optimize selection of neoadjuvant therapy [49].

\section{Monitoring response to neoadjuvant chemotherapy}

A significant response to the primary chemotherapy regimen is observed in about $80 \%$ of cases; however, accurate prediction of a $\mathrm{pCR}$ is challenging. Conventional modalities for assessing chemotherapy response, including clinical examination, mammogram, and breast ultrasound, are incorrect in identifying pCR patients in nearly half of cases. The addition of imaging is clearly more useful than physical examination alone [31,50]. Breast MRI [51,52], positron emission tomography [53], and nuclear medicine sestamibi uptake scans $[54,55]$ have been reported in small series as monitoring strategies with encouraging results.

\section{Immediate breast reconstruction}

LABC traditionally has been perceived as a contraindication to immediate breast reconstruction (IBR), because of concerns regarding adjuvant treatment delays and the cosmetic effects of PMRT to breast reconstruction. Newman and colleagues [56] studied 50 patients with stage IIB to IIIA breast cancer who underwent mastectomy with IBR and found no adverse effect on surgical complication rates compared with 72 mastectomy patients who had LABC without IBR. There was a slightly prolonged interval for adjuvant chemotherapy among reconstructed patients; this did not affect recurrence rates. IBR with implants, however, was associated with more radiationrelated complications; nearly half of the irradiated patients developed contractures or recurrent infections, necessitating implant removal. Other investigators report favorable outcomes for $\mathrm{LABC}$ patients undergoing mastectomy and transverse rectus abdominus myocutaneous (TRAM) flap IBR [57], although at least one recent study suggests that radiated TRAM flaps exhibit late-onset fibrosis and contracture [58]. Delayed reconstruction is therefore, usually preferred in LABC patients undergoing mastectomy, because of the substantial likelihood that PMRT will be necessary, and the potential damaging effects of radiating the reconstructed breast. Occasionally, LABC patients will require soft tissue coverage of an extensive chest wall defect at mastectomy. In these cases, a latissimus dorsi flap is the most common approach, as this flap is a technically straightforward and provides durable, radiationtolerant coverage. A latissimus dorsi flap used for chest wall coverage however, will usually not have the appearance of a reconstructed breast.

\section{Locoregional irradiation for locally advanced breast cancer patients treated with neoadjuvant chemotherapy}

The American Society of Clinical Oncology recommends PMRT for all patients who have four or more metastatic axillary lymph nodes based 
upon axillary surgical findings at presentation (without neoadjuvant chemotherapy), and that PMRT should be considered for any case of operable LABC [42]. In the setting of neoadjuvant therapy, the precise initial pathologic staging is unknown. Because PMRT appears to provide an outcome advantage as adjuvant treatment for surgically resected high-risk disease, a valid question arises regarding the possibility that neoadjuvant chemotherapy might impair the ability to identify these patients.

Patients who have at least four metastatic lymph nodes or $5 \mathrm{~cm}$ of residual disease in the breast after chemotherapy clearly benefit from locoregional irradiation, and all lumpectomy patients require breast irradiation. A conservative (and aggressive) approach would be to recommend radiation to all patients that present with $\mathrm{LABC}$, regardless of chemotherapy response. However, patients with little or no residual breast/axillary disease after chemotherapy may not derive a significant benefit from regional nodal irradiation. Existing data are limited regarding whether or not comprehensive irradiation is absolutely necessary to achieve optimal locoregional control of disease in patients presenting with LABC, but in whom a substantial degree of downstaging occurred with neoadjuvant chemotherapy.

Mamounas and colleagues [59] reported patterns of locoregional failure among NSABP B-18 participants, where stage I to III breast cancer patients were randomized to either preoperative or postoperative chemotherapy. Study design prohibited postmastectomy irradiation, and lumpectomy patients received breast irradiation only (ie, without any regional irradiation). Predictors of locoregional failure were the same in both arms of the study, with four or more metastatic axillary nodes identifying patients who clearly benefit from chest wall irradiation regardless of whether or not the patient received chemotherapy prior to surgery. Thus, the NSABP B-18 data suggest that surgical pathology indications for locoregional irradiation are the same for patients that receive neoadjuvant chemotherapy and those that receive postoperative chemotherapy. In contrast, data from the M.D. Anderson Cancer Center suggest that even among patients with a complete response to neoadjuvant chemotherapy, the presenting stage of disease is predictive for risk of locoregional failure, and that this feature should also be taken into account when deciding on radiation needs. In clinical practice, the oncology team should review each patient in a multidisciplinary fashion, and discussions regarding the complete multimodality management (including final radiation planning) should begin at presentation [60].

\section{Integration of lymphatic mapping/sentinel lymph node biopsy into neoadjuvant chemotherapy protocols}

Sentinel node biopsy in cases of LABC has been approached with concerns that tumor embolization from a tumor might obstruct and alter lymphatic drainage, resulting in either misidentification of the SLN or an altogether failed mapping. Bedrosian and colleagues [61] and Chung and colleagues 
[62] reported excellent SLN identification rates (99\% and 100\%, respectively), and low false-negative rates (3\% for both studies) in their respective series of LABC. Standard axillary lymph node dissection (ALND) however, remains recommended as definitive axillary staging in surgical programs that are still in the learning curve phase of lymphatic mapping for breast cancer.

Most LABC patients are treated with neoadjuvant chemotherapy, and the issue of whether sentinel node staging should be performed before or after neoadjuvant chemotherapy is widely-debated. The earliest studies of SLN biopsy in LABC were performed after delivery of the neoadjuvant chemotherapy, concurrent with the definitive breast surgery. Table 3 [63-76] tabulates the findings of multiple studies where a SLN biopsy was performed with a concomitant ALND after neoadjuvant chemotherapy. The false negative rates range from $0 \%$ to $40 \%$, and are influenced by institutional learning curve, sample size of node-positive cases (which serves as the denominator in the false negative fraction), and primary histopathology (with inflammatory breast cancers having the highest false negative rate). The largest series was reported by the multi-institutional NSABP B-27 study, where more than 400 patients underwent lymphatic mapping and SLN after preoperative chemotherapy. In this study, the SLN identification rate was $85 \%$, and the falsenegative rate $11 \%$. Although these rates are similar to reported multi-center results of lymphatic mapping performed in the primary surgery setting, the broad variation in single-institution results have left many oncology teams skeptical regarding the accuracy of a post-neoadjuvant chemotherapy sentinel lymph node biopsy in cases of LABC.

Because of ongoing uncertainty regarding the accuracy of SLN biopsy after neoadjuvant chemotherapy, several oncology teams have opted to routinely perform the staging SLN biopsy prior to delivery of the neoadjuvant chemotherapy. Some of these studies are summarized in Table 4 [77-79]. As shown by Olilla and colleagues [79], in a study where all patients underwent a pre-neoadjuvant chemotherapy sentinel lymph node biopsy and a postneoadjuvant chemotherapy ALND (regardless of initial sentinel node results), patients that are node-negative at presentation uniformly remain node-negative after chemotherapy. Although this approach subjects patients to an additional operation, it does help to stratify the initial extent of disease. Nodal status is important in planning chemotherapy and for determining regional radiation benefit. Practice standards mandate that preinduction SLN-positive patients undergo completion ALND after neoadjuvant chemotherapy, but a significant proportion of these procedures will be negative for residual axillary nodal disease, as preoperative chemotherapy sterilizes axillary metastases in about $25 \%$ of cases. The advantages and disadvantages of performing a sentinel lymph node biopsy before versus after neoadjuvant chemotherapy are discussed further in the chapter that focuses on neoadjuvant chemotherapy for breast cancer. Furthermore, axillary metastases are limited to the sentinel node(s) in $25-60 \%$ of cases, and these patients will also have a negative post-neoadjuvant chemotherapy ALND. 
Table 3

Studies of sentinel lymph node biopsy performed after neoadjuvant chemotherapy

\begin{tabular}{|c|c|c|c|c|c|}
\hline Study & $\begin{array}{l}\mathrm{T} \\
\text { status }\end{array}$ & $\begin{array}{l}\text { Sample } \\
\text { size }\end{array}$ & $\begin{array}{l}\text { Sentinel node } \\
\text { identification } \\
\text { rate }\end{array}$ & $\begin{array}{l}\text { False- } \\
\text { negative } \\
\text { rate }\end{array}$ & $\begin{array}{l}\text { Metastases } \\
\text { limited to } \\
\text { sentinel } \\
\text { node(s) }\end{array}$ \\
\hline $\begin{array}{l}\text { Breslin, } \\
2000 \text { [63] }\end{array}$ & 2,3 & 51 & $85 \%(42 / 51)$ & $12 \%(3 / 25)$ & $40 \%(10 / 25)$ \\
\hline $\begin{array}{l}\text { Nason, } \\
2000 \text { [64] }\end{array}$ & 2,3 & 15 & $87 \%(13 / 15)$ & $33 \%(3 / 9)$ & $\geq 11 \% *(\geq 1 / 9)$ \\
\hline $\begin{array}{l}\text { Haid, } 2001 \\
\quad[65]\end{array}$ & $1-3$ & 33 & $88 \%(29 / 33)$ & $0 \%(0 / 22)$ & $50 \%(11 / 22)$ \\
\hline $\begin{array}{r}\text { Fernandez, } \\
2001[66]\end{array}$ & $1-4$ & 40 & $90 \%(36 / 40)$ & $20 \%(4 / 20)$ & $20 \%(4 / 20)$ \\
\hline $\begin{array}{l}\text { Tafra, } 2001 \\
\text { [67] }\end{array}$ & 1,2 & 29 & $93 \%(27 / 29)$ & $0 \%(0 / 15)$ & NR \\
\hline \multirow[t]{2}{*}{$\begin{array}{l}\text { Stearns, } \\
\quad 2002[68]\end{array}$} & 3,4 & $\begin{array}{l}\text { T4d } \\
\text { (inflammatory) }\end{array}$ & $75 \%(6 / 8)$ & $40 \%(2 / 5)$ & $24 \%(5 / 21)$ \\
\hline & & Noninflammatory 26 & $88 \%(23 / 26)$ & $6 \%(1 / 16)$ & \\
\hline $\begin{array}{l}\text { Julian, } 2002 \\
\text { [69] }\end{array}$ & $1-3$ & 34 & $91 \%(31 / 34)$ & $0 \%(0 / 12)$ & $42 \%(5 / 12)$ \\
\hline $\begin{array}{l}\text { Miller, } 2002 \\
\text { [70] }\end{array}$ & $1-3$ & 35 & $86 \%(30 / 35)$ & $0 \%(0 / 9)$ & $44 \%(4 / 9)$ \\
\hline $\begin{array}{l}\text { Brady, } 2002 \\
{[71]}\end{array}$ & $1-3$ & 14 & $93 \%(13 / 14)$ & $0 \%(0 / 10)$ & $60 \%(6 / 10)$ \\
\hline $\begin{array}{l}\text { Piato, } 2003 \\
\quad[72]\end{array}$ & 1,2 & 42 & $98 \%(41 / 42)$ & $17 \%(3 / 18)$ & $0 \%(0 / 18)$ \\
\hline $\begin{array}{l}\text { Balch, } 2003 \\
\quad[73]\end{array}$ & $2-4$ & 32 & $97 \%(31 / 32)$ & $5 \%(1 / 19)$ & $56 \%(10 / 18)$ \\
\hline $\begin{array}{l}\text { Schwartz, } \\
2003 \text { [74] }\end{array}$ & $1-3$ & 21 & $100 \%(21 / 21)$ & $9 \%(1 / 11)$ & $64 \%(7 / 11)$ \\
\hline $\begin{array}{l}\text { Reitsamer, } \\
2003 \text { [75] }\end{array}$ & 2,3 & 30 & $87 \%(26 / 30)$ & $7 \%(1 / 15)$ & $53 \%(8 / 15)$ \\
\hline $\begin{array}{l}\text { Mamounas, } \\
2005[76]\end{array}$ & $1-3$ & 428 & $85 \%(363 / 428)$ & $11 \%(15 / 140)$ & $50 \%(70 / 140)$ \\
\hline
\end{tabular}

At the University of Michigan, staging of LABC patients undergo a comprehensive evaluation of the axilla at presentation and after devlivery of the neoadjuvant chemotherapy [80]. Fig. 1 summarizes the current University of Michigan Breast Care Center treatment algorithm for the local, regional, and systemic management of patients presenting with LABC. Axillary ultrasound is obtained at presentation, and morphologically suspicious nodes undergo FNA; a negative ultrasound prompts a SLN biopsy before neoadjuvant chemotherapy. Upon completion of chemotherapy, patients with a negative prechemotherapy axillary work-up do not undergo ALND. Patients with documented prechemotherapy nodal disease (by either axillary FNA or sentinel lymph node biopsy) axillary disease undergo SLN biopsy and concomitant ALND at the time of their definitive surgery. This approach stratifies patients into three categories: node-negative, node-positive down-staged to 
Table 4

Results of sentinel lymph node biopsy performed before delivery of neoadjuvant chemotherapy

Prechemotherapy sentinel lymph node (SLN)

biopsy results

Postchemotherapy status

\begin{tabular}{|c|c|c|c|c|c|}
\hline Study & $\begin{array}{l}\text { Sample } \\
\text { size }\end{array}$ & SLN ID rate & SLN-positive (\%) & $\begin{array}{l}\text { Management } \\
\text { strategy }\end{array}$ & $\begin{array}{l}\text { Postchemotherapy } \\
\text { ALNDs negative for } \\
\text { residual metastases (\%) }\end{array}$ \\
\hline $\begin{array}{l}\text { Zirngibl, et al } \\
2002 \text { [77] }\end{array}$ & 15 & $14 / 15(93 \%)$ & $6 / 14(43 \%)$ & $\begin{array}{l}\text { Completion ALND in SLN-positive } \\
\text { patients only }\end{array}$ & $6 / 6(100 \%)$ \\
\hline $\begin{array}{l}\text { Sabel, et al } \\
2003[78]\end{array}$ & 24 & $24 / 24(100 \%)$ & $10 / 24(42 \%)$ & $\begin{array}{l}\text { Completion ALND in SLN-positive } \\
\text { patients only }\end{array}$ & $3 / 10(30 \%)$ \\
\hline $\begin{array}{r}\text { Olilla, et al } \\
2003 \text { [79] }\end{array}$ & 22 & $22 / 22(100 \%)$ & $10 / 22(45 \%)$ & Completion ALND in all patients & $\begin{array}{l}\text { 12 SLN-negative patients: } 12 / 12 \\
(100 \%) 10 \text { SLN-positive } \\
\text { patients: } 6 / 10(60 \%)\end{array}$ \\
\hline
\end{tabular}




\begin{tabular}{|l|}
\hline $\begin{array}{l}\text { Bilateral mammogram, } \\
\text { Ultrasound of breast mass and } \\
\text { ispilateral axilla }\end{array}$ \\
\hline $\begin{array}{l}\text { Percutaneous core needle biopsy of } \\
\text { breast mass and ultrasound-guided } \\
\text { fine needle aspiration biopsy of any } \\
\text { suspicious nodes. If potential } \\
\text { lumpectomy candidate mark biopsy } \\
\text { site with clip; obtain adequate tissue } \\
\text { for hormone receptor staining and } \\
\text { HER2/neu staining }\end{array}$ \\
\hline
\end{tabular}

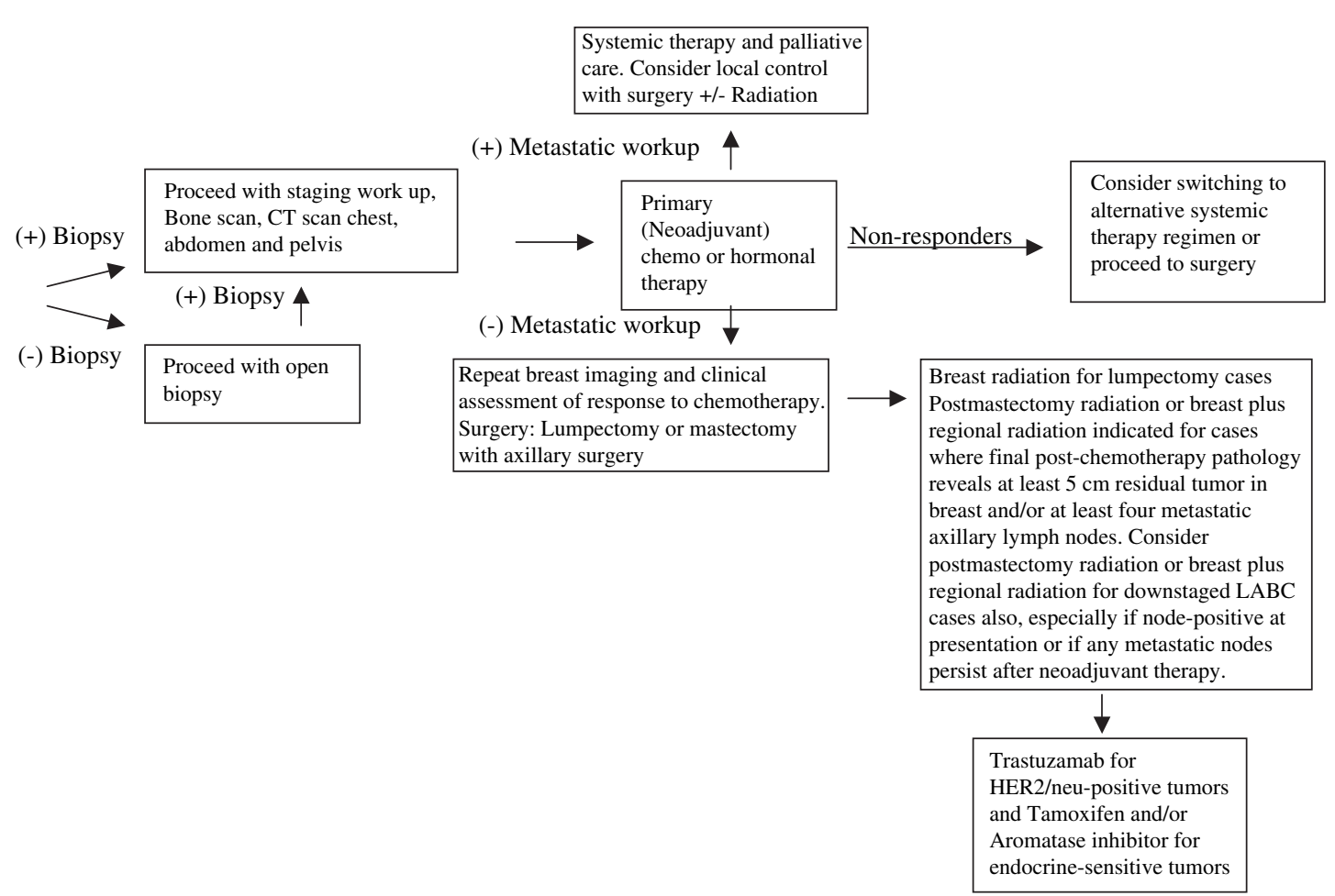

Fig. 1. Suggested diagnostic and treatment algorithm for locally advanced breast cancer. Individual programs should develop a consensus opinion from the multidisciplinary team regarding incorporation of sentinel lymph node biopsy into the neoadjuvant chemotherapy treatment sequence. 
node-negative, and node-positive with chemo-resistant disease. Thus far, the final SLN biopsy appears to correlate well with the final axillary status, suggesting that lymphatic mapping is an accurate identifier of patients who have residual nodal metastases after induction chemotherapy [81]. In the future, we hope to avoid the completion ALND in the patients whose final (post-chemotherapy) sentinel lymph node biopsy indicates that their initial node-positive disease has been downstaged to node-negative status.

\section{Postoperative systemic therapy}

Patients with hormone receptor-positive breast cancer should receive at least 5 years of either tamoxifen or an aromatase inhibitor. Aromatase inhibitors should be given only to postmenopausal women, as these drugs do not block estrogen production from functioning ovaries. Any woman of unknown menstrual status can have ovarian function assessed by measurement of serum follicle-stimulating hormone (FSH), luteinizing hormone (LH), and estradiol levels. The role of ovarian ablation/suppression for premenopausal, hormone receptor-positive breast cancer patients is not yet defined. Tumors overexpressing HER2/neu also require treatment with adjuvant trastuzamab $[82,83]$.

\section{Management of locoregional recurrences}

Chest wall recurrence following mastectomy, or any postlumpectomy recurrence requiring chest wall resection historically has been perceived as a grave event, indicating aggressive tumor biology. Downey and colleagues [84] and Chagpar and colleagues [85] recently reviewed the Memorial Sloan Kettering and Anderson experiences in managing this relapse pattern. These investigators reported that prolonged survival can be achieved when managed with aggressive resection. Five-year overall survival was $35 \%$ at Memorial and $47 \%$ at Anderson when chest wall recurrence was an isolated failure. Improved survival was associated with a disease-free interval of at least 2 years, node-negative disease, and a less than $4 \mathrm{~cm}$ recurrence focus. Resections sometimes included sternum and/or ribs, but surgical morbidity was low.

\section{Summary}

In summary, locally advanced breast cancer is defined as bulky T3 and T4 tumors of the breast, or breast cancer associated with matted axillary (N2) or supraclavicular (N3) adenopathy. Overall outcome and local control rates have improved markedly with multimodal therapy, including neoadjuvant chemotherapy plus surgery and locoregional radiation. Additional postoperative systemic treatments are determined by primary tumor 
molecular markers. BCT may be offered to selected patients after downstaging by neoadjuvant chemotherapy. Treatment with induction chemotherapy can stratify prognosis better based upon pathological response. Ongoing studies are underway to define the optimal induction chemotherapy regimen for maximizing response rates. Incorporation of lymphatic mapping into neoadjuvant chemotherapy protocols requires further study.

\section{References}

[1] Olivotto IA, Chua B, Allan SJ, et al. Long-term survival of patients with supraclavicular metastases at diagnosis of breast cancer. J Clin Oncol 2003;21:851-4.

[2] Brito RA, Valero V, Buzdar AU, et al. Long-term results of combined-modality therapy for locally advanced breast cancer with ipsilateral supraclavicular metastases: the University of Texas M.D. Anderson Cancer Center experience. J Clin Oncol 2001;19:628-33.

[3] Singletary SE, Allred C, Ashley P, et al. Revision of the American Joint Committee on Cancer staging system for breast cancer. J Clin Oncol 2002;20:3628-36.

[4] National Cancer Data Base, 1998-2004. Available at: http://web.facs.org/ncdbbmr/ ncdbbenchmarks8.cfm. Accessed March 1, 2007.

[5] Haagensen C, Stout A. Carcinoma of the breast II. Criteria of operability. Ann Surg 1943; 118:859.

[6] Harris JR, Sawicka J, Gelman R, et al. Management of locally advanced carcinoma of the breast by primary radiation therapy. Int J Radiat Oncol Biol Phys 1983;9:345-9.

[7] Rao DV, Bedwinek J, Perez C, et al. Prognostic indicators in stage III and localized stage IV breast cancer. Cancer 1982;50:2037-43.

[8] Rubens RD, Armitage P, Winter PJ, et al. Prognosis in inoperable stage III carcinoma of the breast. Eur J Cancer 1977;13:805-11.

[9] Townsend CM Jr, Abston S, Fish JC. Surgical adjuvant treatment of locally advanced breast cancer. Ann Surg 1985;201:604-10.

[10] Arnold DJ, Lesnick GJ. Survival following mastectomy for stage III breast cancer. Am J Surg 1979; 137:362-6.

[11] Montague ED, Fletcher GH. Local regional effectiveness of surgery and radiation therapy in the treatment of breast cancer. Cancer 1985;55:2266-72.

[12] Broadwater JR, Edwards MJ, Kuglen C, et al. Mastectomy following preoperative chemotherapy. Strict operative criteria control operative morbidity. Ann Surg 1991;213:126-9.

[13] Danforth DN Jr, Lippman ME, McDonald H, et al. Effect of preoperative chemotherapy on mastectomy for locally advanced breast cancer. Am Surg 1990;56:6-11.

[14] McCready DR, Hortobagyi GN, Kau SW, et al. The prognostic significance of lymph node metastases after preoperative chemotherapy for locally advanced breast cancer. Arch Surg 1989;124:21-5.

[15] De Lena M, Varini M, Zucali R, et al. Multimodal treatment for locally advanced breast cancer. Result of chemotherapy-radiotherapy versus chemotherapy-surgery. Cancer Clin Trials 1981;4:229-36.

[16] Perloff M, Lesnick GJ, Korzun A, et al. Combination chemotherapy with mastectomy or radiotherapy for stage III breast carcinoma: a Cancer and Leukemia Group B study. J Clin Oncol 1988;6:261-9.

[17] Papaioannou A, Lissaios B, Vasilaros S, et al. Pre- and postoperative chemoendocrine treatment with or without postoperative radiotherapy for locally advanced breast cancer. Cancer 1983;51:1284-90.

[18] Hortobagyi GN, Ames FC, Buzdar AU, et al. Management of stage III primary breast cancer with primary chemotherapy, surgery, and radiation therapy. Cancer 1988;62:2507-16. 
[19] Lippman ME, Sorace RA, Bagley CS, et al. Treatment of locally advanced breast cancer using primary induction chemotherapy with hormonal synchronization followed by radiation therapy with or without debulking surgery. NCI Monogr 1986;153-9.

[20] Valagussa $\mathrm{P}$, Zambetti M, Bignami $\mathrm{P}$, et al. T3b-T4 breast cancer: factors affecting results in combined modality treatments. Clin Exp Metastasis 1983;1:191-202.

[21] Olson JE, Neuberg D, Pandya KJ, et al. The role of radiotherapy in the management of operable locally advanced breast carcinoma: results of a randomized trial by the Eastern Cooperative Oncology Group. Cancer 1997;79:1138-49.

[22] Cance WG, Carey LA, Calvo BF, et al. Long-term outcome of neoadjuvant therapy for locally advanced breast carcinoma: effective clinical downstaging allows breast preservation and predicts outstanding local control and survival. Ann Surg 2002;236:295-302 [discussion: 3].

[23] Mauriac L, Durand M, Avril A, et al. Effects of primary chemotherapy in conservative treatment of breast cancer patients with operable tumors larger than $3 \mathrm{~cm}$. Results of a randomized trial in a single centre. Ann Oncol 1991;2:347-54.

[24] Mauriac L, MacGrogan G, Avril A, et al. Neoadjuvant chemotherapy for operable breast carcinoma larger than $3 \mathrm{~cm}$ : a unicentre randomized trial with a 124-month median follow-up. Institut Bergonie Bordeaux Groupe Sein (IBBGS). Ann Oncol 1999;10:47-52.

[25] Schwartz GF, Birchansky CA, Komarnicky LT, et al. Induction chemotherapy followed by breast conservation for locally advanced carcinoma of the breast. Cancer 1994;73:362-9.

[26] Schwartz GF, Lange AK, Topham AK. Breast conservation following induction chemotherapy for locally advanced carcinoma of the breast (stages IIB and III). A surgical perspective. Surg Oncol Clin N Am 1995;4:657-69.

[27] Powles TJ, Hickish TF, Makris A, et al. Randomized trial of chemoendocrine therapy started before or after surgery for treatment of primary breast cancer. J Clin Oncol 1995; 13:547-52.

[28] Makris A, Powles TJ, Ashley SE, et al. A reduction in the requirements for mastectomy in a randomized trial of neoadjuvant chemoendocrine therapy in primary breast cancer. Ann Oncol 1998;9:1179-84.

[29] Fisher B, Brown A, Mamounas E, et al. Effect of preoperative chemotherapy on localregional disease in women with operable breast cancer: findings from National Surgical Adjuvant Breast and Bowel Project B-18. J Clin Oncol 1997;15:2483-93.

[30] Wolmark N, Wang J, Mamounas E, et al. Preoperative chemotherapy in patients with operable breast cancer: nine-year results from National Surgical Adjuvant Breast and Bowel Project B-18. J Natl Cancer Inst Monogr 2001;96-102.

[31] Newman LA, Buzdar AU, Singletary SE, et al. A prospective trial of preoperative chemotherapy in resectable breast cancer: predictors of breast conservation therapy feasibility. Ann Surg Oncol 2002;9:228-34.

[32] Bedrosian I, Bedi D, Kuerer HM, et al. Impact of clinicopathological factors on sensitivity of axillary ultrasonography in the detection of axillary nodal metastases in patients with breast cancer. Ann Surg Oncol 2003;10:1025-30.

[33] Krishnamurthy S, Sneige N, Bedi DG, et al. Role of ultrasound-guided fine-needle aspiration of indeterminate and suspicious axillary lymph nodes in the initial staging of breast carcinoma. Cancer 2002;95:982-8.

[34] Newman LA, Kuerer HM, Fornage B, et al. Adverse prognostic significance of infraclavicular lymph nodes detected by ultrasonography in patients with locally advanced breast cancer. Am J Surg 2001;181:313-8.

[35] Samant R, Ganguly P. Staging investigations in patients with breast cancer: the role of bone scans and liver imaging. Arch Surg 1999;134:551-3 [discussion: 4].

[36] Khan SA, Stewart AK, Morrow M. Does aggressive local therapy improve survival in metastatic breast cancer? Surgery 2002;132:620-7.

[37] Fisher B, Bryant J, Wolmark N, et al. Effect of preoperative chemotherapy on the outcome of women with operable breast cancer. J Clin Oncol 1998;16:2672-85. 
[38] Kuerer HM, Newman LA, Smith TL, et al. Clinical course of breast cancer patients with complete pathologic primary tumor and axillary lymph node response to doxorubicin-based neoadjuvant chemotherapy. J Clin Oncol 1999;17:460-9.

[39] Singletary SE, McNeese MD, Hortobagyi GN. Feasibility of breast conservation surgery after induction chemotherapy for locally advanced breast carcinoma. Cancer 1992;69:2849-52.

[40] Scholl SM, Fourquet A, Asselain B, et al. Neoadjuvant versus adjuvant chemotherapy in premenopausal patients with tumours considered too large for breast-conserving surgery: preliminary results of a randomised trial: S6. Eur J Cancer 1994;30A:645-52.

[41] Scholl SM, Pierga JY, Asselain B, et al. Breast tumour response to primary chemotherapy predicts local and distant control as well as survival. Eur J Cancer 1995;31A:1969-75.

[42] Recht A, Edge SB, Solin LJ, et al. Postmastectomy radiotherapy: clinical practice guidelines of the American Society of Clinical Oncology. J Clin Oncol 2001;19:1539-69.

[43] Mamounas E. Preliminary results of the NSABP B-27 Trial. Presented at the San Antonio Breast Cancer Symposium 2001. San Antonio (TX), December 2001.

[44] Green M, Buzdar AU. Results from a prospective trial of neoadjuvant paclitaxel and doxorubicin for breast cancer. Presented at the American Society of Clinical Oncology 2002 Symposium. Orlando (FL), May 2002.

[45] Smith IC, Heys SD, Hutcheon AW, et al. Neoadjuvant chemotherapy in breast cancer: significantly enhanced response with docetaxel. J Clin Oncol 2002;20:1456-66.

[46] Heys SD, Hutcheon AW, Sarkar TK, et al. Neoadjuvant docetaxel in breast cancer: 3-year survival results from the Aberdeen trial. Clin Breast Cancer 2002;2(3 Suppl):S69-74.

[47] Dixon JM, Anderson TJ, Miller WR. Neoadjuvant endocrine therapy of breast cancer: a surgical perspective. Eur J Cancer 2002;38:2214-21.

[48] Ellis M, Coop A, Singh B. Letrozole is more effective neoadjuvant endocrine therapy than tamoxifen for ErbB-1 and/or ErbB-2-positive, estrogen receptor-positive primary breast cancer: evidence from a phase III randomized trial. J Clin Oncol 2001;19:3808-16.

[49] Pusztai L, Ayers M, Stec J, et al. Clinical application of cDNA microarrays in oncology. Oncologist $2003 ; 8: 252-8$.

[50] Helvie MA, Joynt LK, Cody RL, et al. Locally advanced breast carcinoma: accuracy of mammography versus clinical examination in the prediction of residual disease after chemotherapy. Radiology 1996;198:327-32.

[51] Delille JP, Slanetz PJ, Yeh ED, et al. Invasive ductal breast carcinoma response to neoadjuvant chemotherapy: noninvasive monitoring with functional MR imaging pilot study. Radiology 2003;228:63-9.

[52] Abraham D, Jones R, Jones S, et al. Evaluation of neoadjuvant chemotherapeutic response of locally advanced breast cancer by magnetic resonance imaging. Cancer 1996;78:91-100.

[53] Wahl R, Zasadny K, Helvie M. Metabolic monitoring of breast cancer chemohormonal therapy using positron emission tomography: initial evaluation. J Clin Oncol 1993;11:2101-11.

[54] Mezi S, Primi F, Capoccetti F, et al. In vivo detection of resistance to anthracycline-based neoadjuvant chemotherapy in locally advanced and inflammatory breast cancer with technetium-99m sestamibi scintimammography. Int J Oncol 2003;22:1233-40.

[55] Wilczek B, von Schoultz E, Bergh J, et al. Early assessment of neoadjuvant chemotherapy by FEC courses of locally advanced breast cancer using 99mTc-MIBI. Acta Radiol 2003;44: $284-7$.

[56] Newman LA, Kuerer HM, Hunt KK, et al. Feasibility of immediate breast reconstruction for locally advanced breast cancer. Ann Surg Oncol 1999;6:671-5.

[57] Styblo T, Lewis M, Carlson G, et al. Immediate breast reconstruction for stage III breast cancer using transverse rectus abdominis musculotaneous (TRAM) flap. Ann Surg Oncol 1996;3:375-80.

[58] Tran NV, Chang DW, Gupta A, et al. Comparison of immediate and delayed free TRAM flap breast reconstruction in patients receiving postmastectomy radiation therapy. Plast Reconstr Surg 2001;108:78-82. 
[59] Mamounas E, Wang J, Bryant J, et al. Patterns of loco-regional failure in patients receiving neoadjuvant chemotherapy: results from NSABP B-18. Presented at the 26th Annual San Antonio Breast Cancer Symposium. San Antonio (TX), December 2003.

[60] Buchholz TA, Katz A, Strom EA, et al. Pathologic tumor size and lymph node status predict for different rates of locoregional recurrence after mastectomy for breast cancer patients treated with neoadjuvant versus adjuvant chemotherapy. Int J Radiat Oncol Biol Phys 2002; 53:880-8.

[61] Bedrosian I, Reynolds C, Mick R, et al. Accuracy of sentinel lymph node biopsy in patients with large primary breast tumors. Cancer 2000;88:2540-5.

[62] Chung M, Ye W, Giuliano A. Role for sentinel lymph node dissection in the management of large ( $>$ or $+5 \mathrm{~cm}$ ) invasive breast cancer. Ann Surg Oncol 2001;8:688-92.

[63] Breslin TM, Cohen L, Sahin A, et al. Sentinel lymph node biopsy is accurate after neoadjuvant chemotherapy for breast cancer. J Clin Oncol 2000;18:3480-6.

[64] Nason KS, Anderson BO, Byrd DR, et al. Increased false-negative sentinel node biopsy rates after preoperative chemotherapy for invasive breast carcinoma. Cancer 2000;89:2187-94.

[65] Haid A, Tausch C, Lang A, et al. Is sentinel lymph node biopsy reliable and indicated after preoperative chemotherapy in patients with breast carcinoma? Cancer 2001;92:1080-4.

[66] Fernandez A, Cortes M, Benito E, et al. Gamma probe sentinel node localization and biopsy in breast cancer patients treated with a neoadjuvant chemotherapy scheme. Nucl Med Commun 2001;22:361-6.

[67] Tafra L, Verbanac K, Lannin D. Preoperative chemotherapy and sentinel lymphadenectomy for breast cancer. Am J Surg 2001;182:312-5.

[68] Stearns V, Ewing CA, Slack R, et al. Sentinel lymphadenectomy after neoadjuvant chemotherapy for breast cancer may reliably represent the axilla except for inflammatory breast cancer. Ann Surg Oncol 2002;9:235-42.

[69] Julian TB, Dusi D, Wolmark N. Sentinel node biopsy after neoadjuvant chemotherapy for breast cancer. Am J Surg 2002;184:315-7.

[70] Miller AR, Thomason VE, Yeh IT, et al. Analysis of sentinel lymph node mapping with immediate pathologic review in patients receiving preoperative chemotherapy for breast carcinoma. Ann Surg Oncol 2002;9:243-7.

[71] Brady E. Sentinel lymph node mapping following neoadjuvant chemotherapy for breast cancer. Breast J 2002;8:97-100.

[72] Piato J, Barros A, Pincerato K, et al. Sentinel lymph node biopsy in breast cancer after neoadjuvant chemotherapy. A pilot study. Eur J Surg Oncol 2002;29:118-20.

[73] Balch GC, Mithani SK, Richards KR, et al. Lymphatic mapping and sentinel lymphadenectomy after preoperative therapy for stage II and III breast cancer. Ann Surg Oncol 2003;10:616-21.

[74] Schwartz GF, Meltzer AJ. Accuracy of axillary sentinel lymph node biopsy following neoadjuvant (induction) chemotherapy for carcinoma of the breast. Breast J 2003;9: 374-9.

[75] Reitsamer R, Peintinger F, Rettenbacher L, et al. Sentinel lymph node biopsy in breast cancer patients after neoadjuvant chemotherapy. J Surg Oncol 2003;84:63-7.

[76] Mamounas EP, Brown A, Anderson S, et al. Sentinel node biopsy after neoadjuvant chemotherapy in breast cancer: results from National Surgical Adjuvant Breast and Bowel Project Protocol B-27. J Clin Oncol 2005;23:2694-702.

[77] Zirngibl C, Steinfeld-Birg D, Vogt H, et al. Sentinel lymph node biopsy before neoadjuvant chemotherapy- conservation of breast and axilla, abstract \#516. San Antonio Breast Cancer Symposium. San Antonio, Texas; December 13, 2002.

[78] Sabel MS, Schott AF, Kleer CG, et al. Sentinel node biopsy prior to neoadjuvant chemotherapy. Am J Surg 2003;186:102-5.

[79] Ollila DW, Neuman HB, Sartor C, et al. Lymphatic mapping and sentinel lymphadenectomy prior to neoadjuvant chemotherapy in patients with large breast cancers. Am J Surg 2005; 190:371-5. 
[80] Khan A, Sabel MS, Nees A, et al. Comprehensive axillary evaluation in neoadjuvant chemotherapy patients with ultrasonography and sentinel lymph node biopsy. Ann Surg Oncol 2005;12:697-704.

[81] Newman EA, Sabel M, Nees A, et al. Sentinel lymph node biopsy following neoadjuvant chemotherapy is Accurate in patients with documented nodal metastases at presentation. Ann Surg Onc, in press.

[82] Piccart-Gebhart MJ, Procter M, Leyland-Jones B, et al. Trastuzumab after adjuvant chemotherapy in HER2-positive breast cancer. N Engl J Med 2005;353:1659-72.

[83] Romond EH, Perez EA, Bryant J, et al. Trastuzumab plus adjuvant chemotherapy for operable HER2-positive breast cancer. N Engl J Med 2005;353:1673-84.

[84] Downey R, Rusch V, Hsu F, et al. Chest wall resection for locally recurrent breast cancer: is it worthwhile? J Thorac Cardiovasc Surg 2000;119:420-8.

[85] Chagpar A, Meric-Bernstam F, Hunt K, et al. Chest wall recurrence after mastectomy does not always portend a dismal outcome. Ann Surg Oncol 2003;10:628-34. 